\title{
DEVELOPMENT OF CERAMIC MICROFILTRATION SUPPORT FROM MOROCCAN SAHARA CLAY
}

\author{
NOURLYAQUIN EL QACEMI ${ }^{1}$, NABIL SAFFAJ ${ }^{* 2}$, RACHID MAMOUNI ${ }^{1}$, \\ NOURREDINE EL BARAKA ${ }^{1}$, HAMID ZIDOUH ${ }^{2}$, MOHAMED AIT BAIH ${ }^{2}$, \\ ABDELATIF LAKNIFLI ${ }^{1}$ \\ ${ }^{1}$ Université Ibn Zohr, Faculté des Sciences, BP 8106 - Cité Dakhla, Agadir, Morocco \\ ${ }^{2}$ Université Ibn Zohr, Faculté Polydisciplinaire, B.P 638, Ouarzazate, Morocco
}

\begin{abstract}
The new ceramic microfiltration support prepared from Moroccan clay (Laayoune region, South of Morocco) is reported in this paper. To optimize the support elaboration conditions, the powder clay is mixed with organic additives and water. The formed paste is shaped by using an extrusion processing and then sintered at $950{ }^{\circ} \mathrm{C}$. The ceramic supports present a porosity and mechanical strength of $44 \%$ and $12 \mathrm{MPa}$ respectively. The layer filtration deposition has been carried out by the slip casting method, in order to test its operation in textile effluents treatment.
\end{abstract}

Keywords: membrane, clay, effluent, Sahara

\section{INTRODUCTION}

Due to their widely application in industrial field, the membrane processes had a great interest in recent years. Filtration whatever, microfiltration or ultrafiltration, is generally referred to by its everlasting service also its disposal capacity of suspended solids and microorganisms [1-3].

The ceramic membranes present several advantages than organic counterpart such as better mechanical strength and thermal and chemical resistances and under aggressive chemicals conditions $[4,5]$.

Unfortunately, the cost of ceramic membranes is too expensive to assure a large application. To overcome this drawback, the new ceramic microfiltration and ultrafiltration membranes, that were produced based on abundant natural materials such as clay, showed significant advantages from an economic point of view [6].

The aim of this work is to elaborate a new membrane support using natural clay from south of Morocco (Laayoune, Sahara). The steps of elaboration of flat ceramic membrane will be described.

The structural characteristics and chemical stability of the membrane was investigated for various sintering temperatures.

Prosity and structural density were also evaluated to optimize the sintering temperature to get the high porous low -cost ceramic membrane. The support was test by filtration of textile effluents.

\footnotetext{
* Corresponding author, email: isaffaj@gmail.com

(c) 2018 Alma Mater Publishing House
} 


\section{MATERIALS AND METHODS}

After removing the stones and heavy particles from the clay, the powder was then dispersed in $2 \mathrm{~L}$ of deionised water for the sedimentation process. The top part was sieved through a $160 \mu \mathrm{m}$ sieve to remove the larger nonclay fractions and to obtain the fine clay fraction.

The sample were dried at $100{ }^{\circ} \mathrm{C}$ and stored in a desiccators. The particle sizing Accusizer model 770 (particle sizing system Santa Barbara) was used to determine the particle size distribution.

The composition of the natural clay was obtained by X-Ray Fluorescence « Panallytical Axios ». The XRD analysis of the treated clay were carried with a X'Pert Pro MPD Panalytical (Cu K ray, Ni Filter).

The sample was heated from room temperature to $950{ }^{\circ} \mathrm{C}$ at a rate of $5{ }^{\circ} \mathrm{C} / \mathrm{min}$ under static atmospheric conditions; $\alpha-\mathrm{Al}_{2} \mathrm{O}_{3}$ was used as reference. The prosity of the support was determined by mercury porosimetry (Micrometrics Autopore II 9215).

\section{RESULTS AND DISCUSSION}

\subsection{Chemical analysis}

The chemical composition of these materials is shown in Table 1. The chemicals analysis reveals that the clay powder is formed of a great amount of silica with alumina and iron and magnesium oxide in lower proportion, however the potassium represent as minority element.

Table 1. Chemical analysis of the clay.

\begin{tabular}{|l|c|c|c|c|c|c|c|}
\hline Oxydes & $\mathrm{SiO}_{2}$ & $\mathrm{Al}_{2} \mathrm{O}_{3}$ & $\mathrm{Fe}_{2} \mathrm{O}_{3}$ & $\mathrm{MgO}$ & $\mathrm{K}_{2} \mathrm{O}$ & $\mathrm{CaO}$ & Lo.I \\
\hline Weight $(\%)$ & 47.17 & 10.88 & 4.98 & 2.80 & 1.39 & 14.62 & 19.4 \\
\hline
\end{tabular}

The particle size distribution is represented in Table 2 . The particle diameter has ranges from 1 to $36 \mu \mathrm{m}$ and more than $70 \%$ of the particles present a diameter less than $5 \mu \mathrm{m}$.

Table 2. Particle size distribution of the clay.

\begin{tabular}{|c|c|}
\hline Diameter $(\mu \mathrm{m})$ & Particle size distribution (\%) \\
\hline$[10,36]$ & 10 \\
\hline$[5,10]$ & 20 \\
\hline$<5$ & 70 \\
\hline
\end{tabular}

\subsection{XRD analysis}

The Figure 1 shows the diffraction patterns of the raw and calcined material at different temperatures. The diffraction of the raw clay revealed a strong presence of silica presented by quartz, and mainly gypsum. On the other hand, kaolinite is the phyllitic phase presented in the sample [7, 8].

The disappearance of all the kaolinite reflections resulted by a heat treatment at $600{ }^{\circ} \mathrm{C}$. This phenomena has already been observed by several authors [9-12], it is the result of dehydroxylation of kaolinite in metakaolin which has a poorly organized structure.

This also results of the absence of diffraction lines, indicating that the reaction is not accompanied by any neocrystallization.

The heat treatment at $1000{ }^{\circ} \mathrm{C}$ led to the appearance of new lines, correlated with the formation of hematite and Mullite due of the transformation of metakaolinite. 


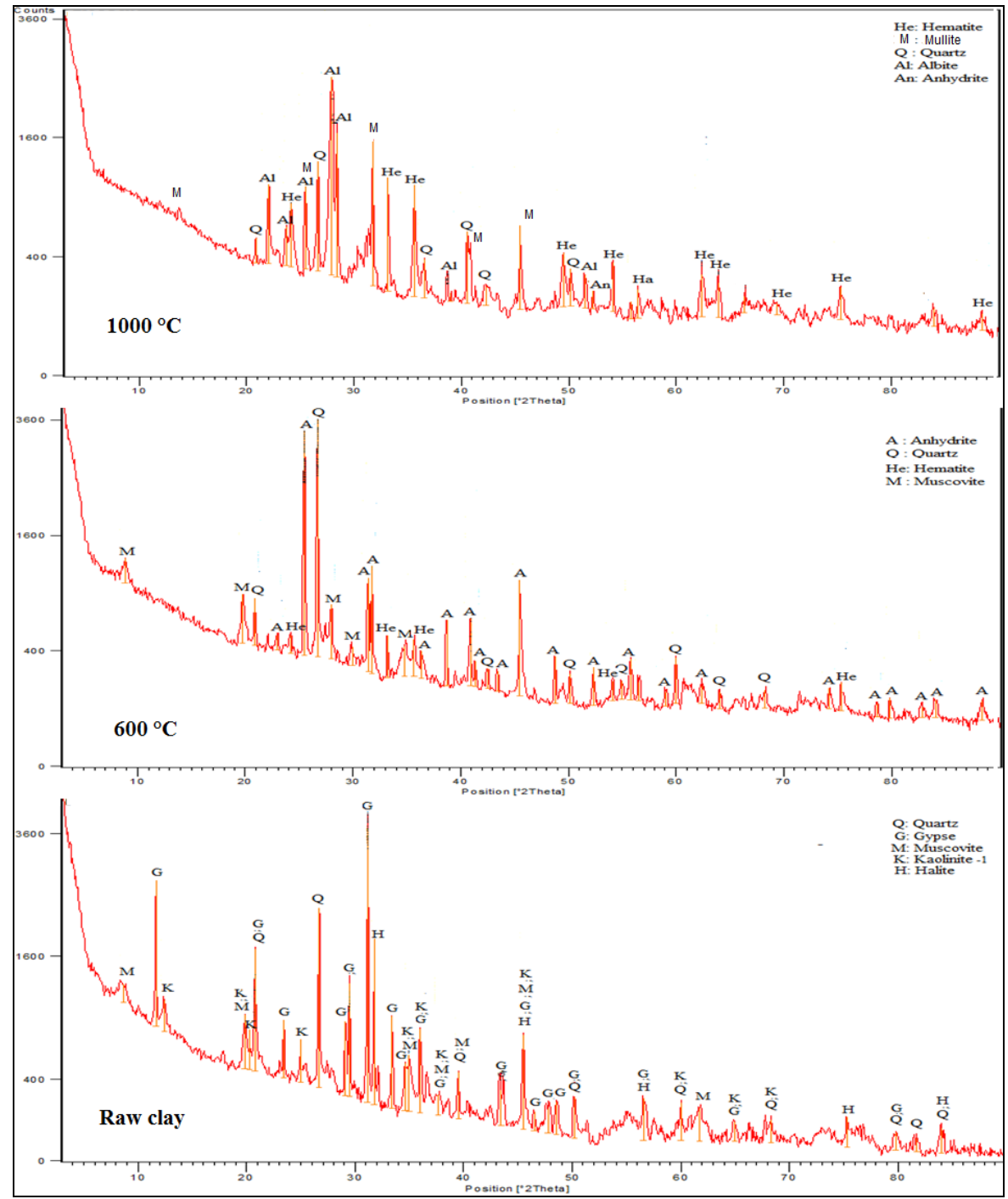

Fig. 1. Diffractograms of the clay at different temperatures.

\subsection{Elaboration of supports based on Moroccan Sahara clay}

The purpose of this study is to realize new membrane's supports, based on natural clay from, Laayoune region (South of Morocco). We have chosen to develop the new support membrane with improved separation properties, high mechanical and thermal stability using inexpressive and naturally abundant materials is of utmost importance for sustainable development and environmental applications.

Before preparing the ceramic paste, the natural clay was crushed and sieved in woven wire sieves of 160 microns. This powder will be blended with organic additives, completely mixed dry to reach an uniform distribution of all components. This mixture in the presence of water enables us to achieve an agglomeration of grains of the desired paste properties (Figure 2).

Table 3. Percentage of each compound in relation to the total mass of powder.

\begin{tabular}{|c|c|c|}
\hline Product & Function & Quantity $(\%$ mass $)$ \\
\hline Clay & Ceramic Powder & 99.44 \\
\hline Amidon & Binder & 0.55 \\
\hline Glycerin & Plasticizer & $0.55 \mathrm{M}$ \\
\hline Water & Solvent & $24.86 \mathrm{M}$ \\
\hline Zusoplast 126/3 & Lubricant & $0.26 \mathrm{M}$ \\
\hline
\end{tabular}




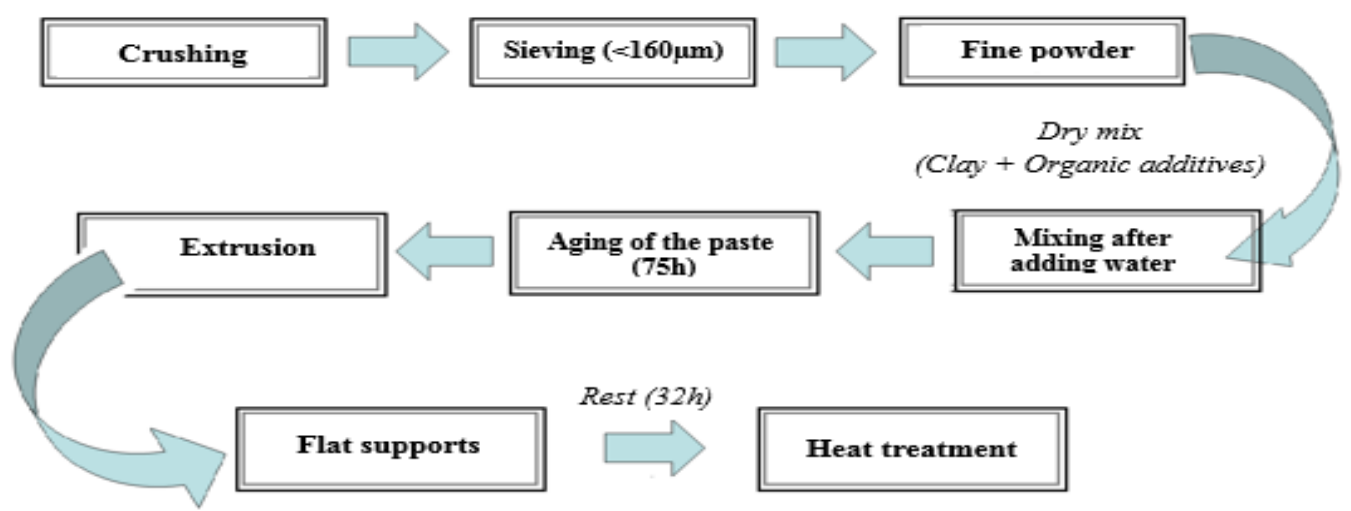

Fig. 2. Schematic of process of membrane support preparation.

After mixing the components composing the ceramic paste (Table 3), the obtained paste was stocked for at least 75 hours in a closed box under high humidity (aging time) to achieve greater consistency and to avoid the formation of air bubbles. The paste was then extruded and calendared into a thin film which was segmented to form a flat disk supports with a diameter of $3.6 \mathrm{~cm}$. The extruded pieces were dried at ambient temperature for 24 hours and placed in an oven at $50{ }^{\circ} \mathrm{C}$ for 24 hours.

To optimize the temperature of sintering to obtain a good porosity and acceptable mechanical strength allow us to work at high pressure, we program a firing in a programmable furnace at different temperature (Figure 3). Consequently, the best properties of the final support are achieved by adjusting the conditions for the sintering.

The heat treatment allowed the definitive consolidation of the moulded discks after removing the organic additions. This treatment is a very important step in the elaboration process, is accompanied with the transformation of initial minerals. For this, should be perfectly suited to the product (composition, geometry).

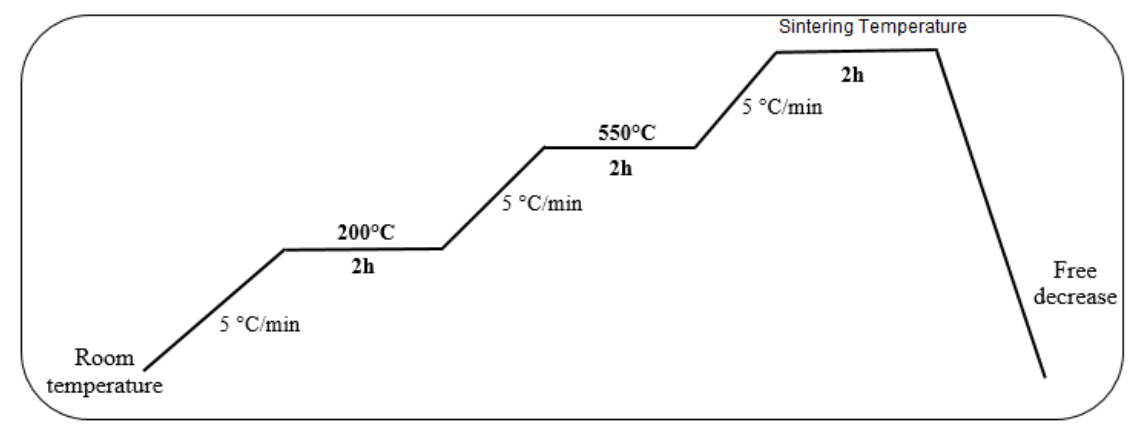

Fig. 3. Scheme of the thermal treatment program used.

The Figure 4 shows the porosity versus the sintering temperature. The porosity of the supports was studied at temperature range between $900-1100{ }^{\circ} \mathrm{C}$. The highest resulting values of porosity were found when the sintering temperature is $950{ }^{\circ} \mathrm{C}$, followed by a sharp decrease when temperature reaches $1100{ }^{\circ} \mathrm{C}$.

The mechanical strength versus the sintering temperature is represented in Figure 5. When the firing temperature increases, the mechanical strength increase and reach $13 \mathrm{MPa}$ at $1050{ }^{\circ} \mathrm{C}$. Above this temperature the mechanical strength continue to increase.

Finally, the best conditions to prepare the support are established for a firing temperature of $950{ }^{\circ} \mathrm{C}$. At this condition, the poosity is $44 \%$ and the mechanical strenghth is $12 \mathrm{MPa}$ (Figure 6). 


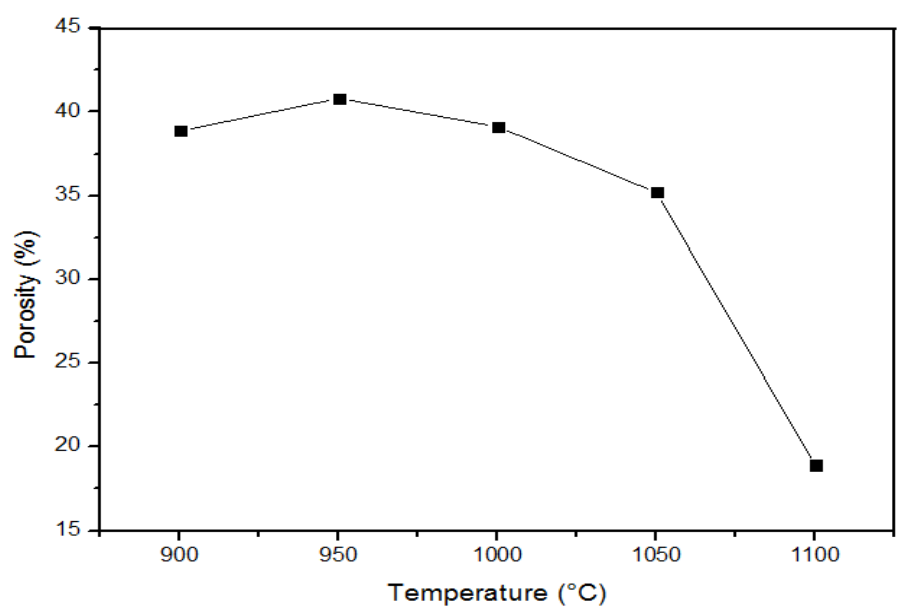

Fig. 4. Porosity versus sintering temperature.

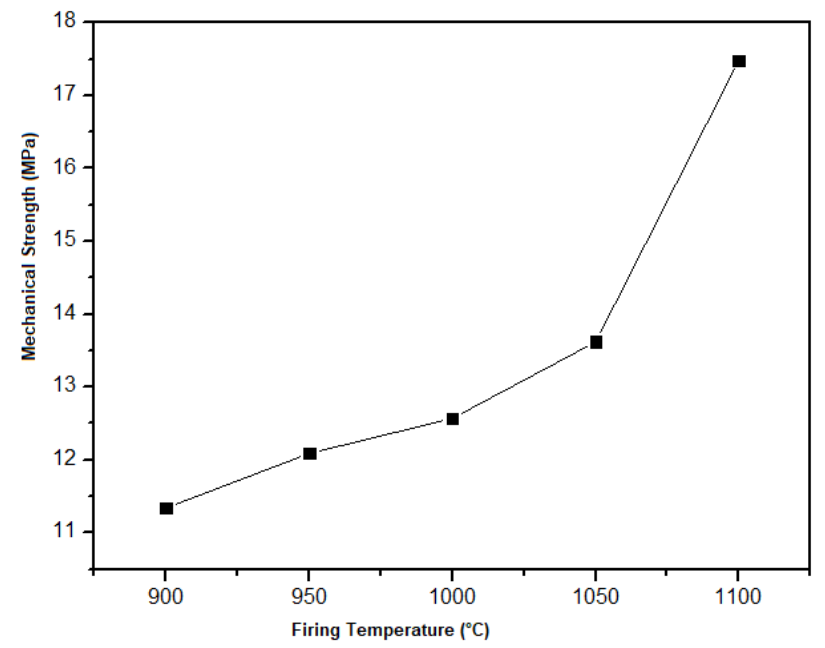

Fig. 5. Mechanical strength versus sintering temperature.

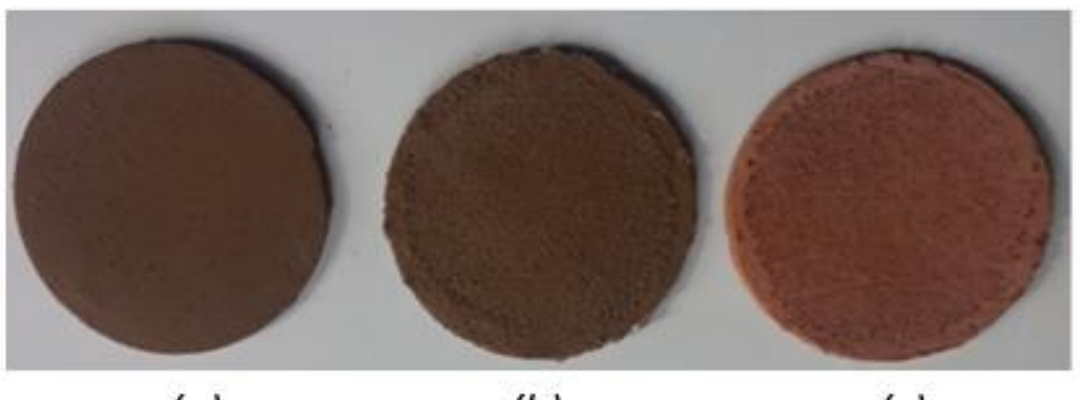

(a)

(b)

(c)

Fig. 6. Images of the flat support: (a) wet; (b) after drying at $40^{\circ} \mathrm{C}$; (c) after sintering at $950^{\circ} \mathrm{C}$.

Corrosion resistance tests were performed on the membrane supports, sintered at $950^{\circ} \mathrm{C}$. Samples were immersed for 8 days in baths of hydrochloric acid solution $(\mathrm{pH}=1.01)$ and $\mathrm{NaOH}(\mathrm{pH}=13.5)$ out at $25^{\circ} \mathrm{C}$. After the time limit of immersion, the samples were washed with water and dried. 
The results of corrosion resistance show that support resisted better in basic medium than in an acidic medium. The weight loss not exceed $2.3 \%$ for 8 days of immersion in a basic. However, in an acidic the weight loss increased to $5.5 \%$.

\subsection{Tests of filtrations}

\subsubsection{Determination of permeability}

The experimental set us of frontal filtration is represented in Figure 7, with membrane support sintered at $\mathrm{T}=$ $950^{\circ} \mathrm{C}$, where they had a $2 \mathrm{~mm}$ thickness and a filtration area of $15.1 \mathrm{~cm}^{2}$. Before the filtration tests, the membrane had been conditioned by immersion in pure distilled water for $24 \mathrm{~h}$. All the filtration experiment was conducted at ambient temperature.

The permeability of distilled water, and the textile effluent clarification were made on the membrane support.

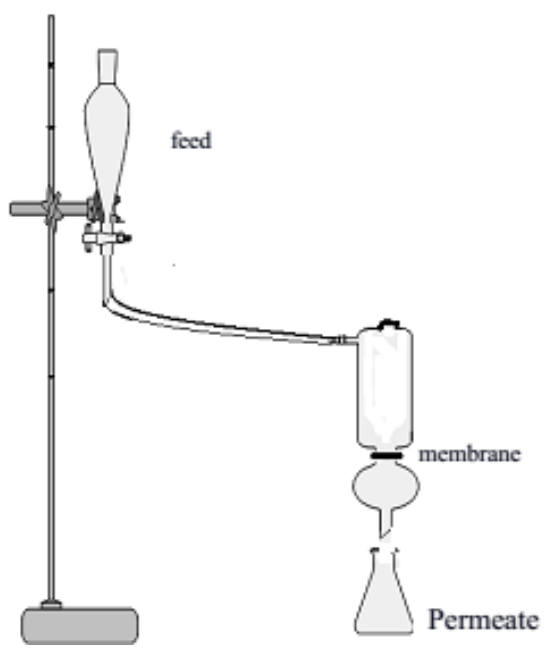

Fig. 7. Scheme of the pilot filtration.

The permeability of distilled water is a key parameter to characterize the membrane supports. For this, we determine the fluxes at different transmembrane pressure $(0.12,0.1,0.08,0.06$ and 0.04 bar $)$.

The water flux through of the membrane depends on the applied pressure. From the curves given the flux versus time represented in Figure 8, the stabilization of the water flux through the membranes takes minimum values at pressures inferior 0.1 bar. The highest resulting value of water flux was found $340 \mathrm{~L} / \mathrm{h} \mathrm{m}^{2}$ at 0.12 bar in $20 \mathrm{~min}$.

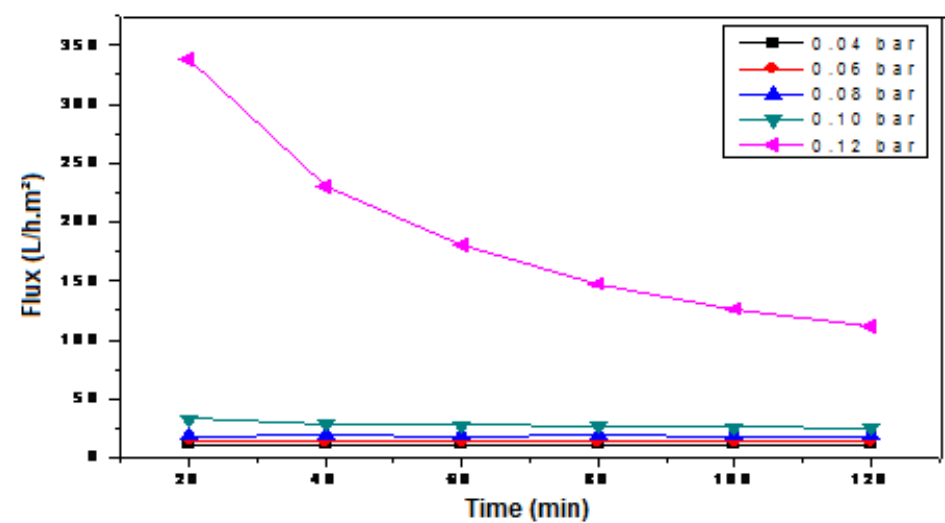

Fig. 8. Water flux versus time of filtration.

The average permeability was determined from the values of flux measured after stabilization of pressure at 0.12 bar. The course of the permeability (Figure 9) shows a maximum value of $281 \mathrm{~L} / \mathrm{h} \mathrm{m}^{2}$ bar, followed by a decrease as a function of time. 


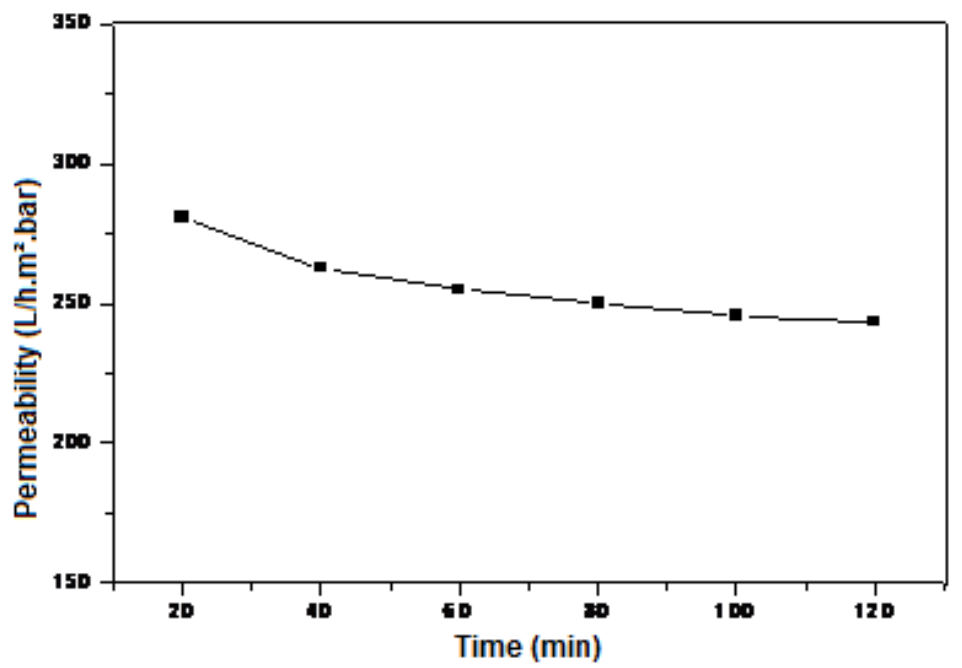

Fig. 9. Water permeability versus time of filtration.

\subsubsection{Textile effluents filtration tests}

The filtration test performance of textile effluents on membranes based on natural clay Moroccan Sahara, were qualified by measuring the turbidity, the conductivity and the $\mathrm{pH}$ in these effluents before and after filtration. The results obtained are summarized in the following Table 4.

The filtration on the supports allows a clarification of the studied effluents. The conductivity reduces from 1553 to $1120 \mu \mathrm{S} / \mathrm{cm}$ and the turbidity reduces dramatically.

Table 4. Characteristics of textile wastewaters and permeate of membrane support.

\begin{tabular}{|c|c|c|c|c|c|}
\hline \multicolumn{2}{|c|}{$\mathrm{pH}$} & \multicolumn{2}{c|}{ Conductivity $(\mu \mathrm{S} / \mathrm{cm})$} & \multicolumn{2}{c|}{ Turbidity (NTU) } \\
\hline Rejection & Permeate & Rejection & Permeate & Rejection & Permeate \\
\hline 7.27 & 8.33 & 1553 & 1120 & 181 & 5.30 \\
\hline
\end{tabular}

\section{5. Development of a flat microfiltration membrane, based on Saharan's clay}

The aim of this part is the development of a microfiltration membrane utilizing the previously prepared supports. The membrane is produced by the slip casting technique where the driving force is a capillary suction. The layer thickness depends on the properties of the used material, such as porosity, capillary pressure, the volume fraction of the solid in the slip [13-15].

The slip intermediate layer was prepared using $10 \%$ weight of the natural clay powder (fraction smaller than 40 microns), a $30 \%$ PVA weight (12\% of aqueous solution weight ) and $60 \%$ of DOLAPIX EC 64 weight, as dispersing agent (aqueous solution of $0.2 \%$ by weight). The dispersion of particles was assured by 30 min ultrasonic agitation.

To coat the ceramic substrate, is then applied to the casting process valve. After the film deposition on the substrate, it is dried at room temperature and then baked at $950{ }^{\circ} \mathrm{C}$, to achieve the filter layer's consolidation. To finally obtained a microfiltration layer with average diameters of $0.45 \mu \mathrm{m}$.

The various production steps of flat microfiltration membrane are summarized in the Figure 10.

The slip (Figure 11) composition is considered to be optimal, when the coating allows the production of thick layers sufficient to assure a complete and homogeneous covering of the wall of the ceramic disks; and this, to improve the disposal of polluting species. 


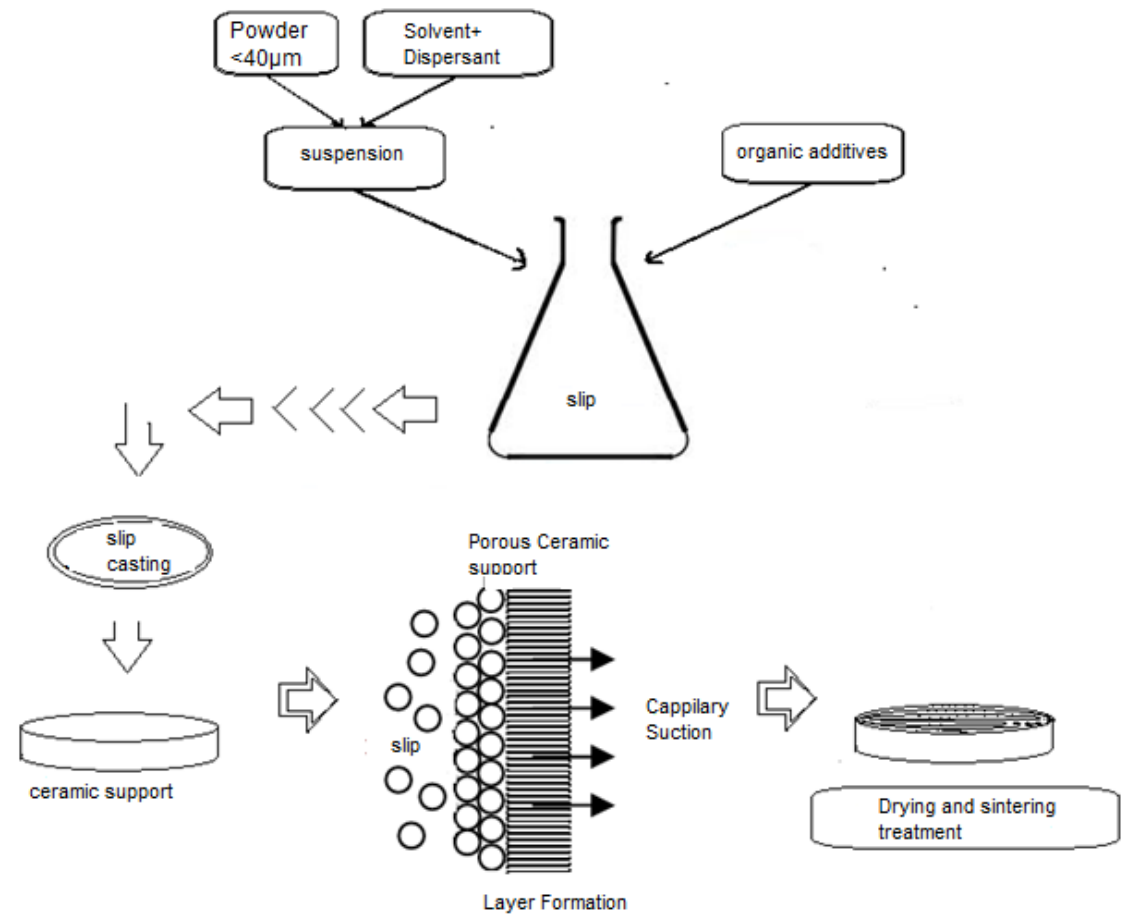

Fig. 10. Steps in the realization of a membrane by the technique of casting of slip.

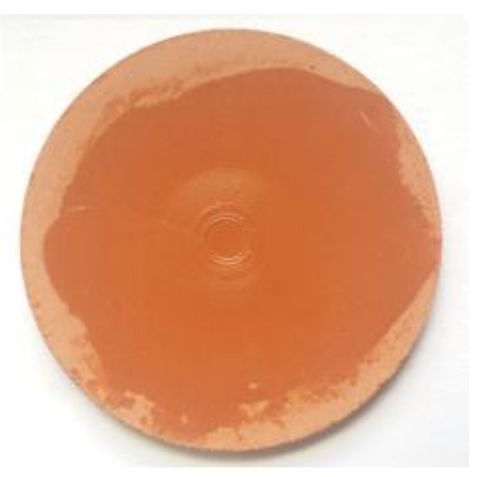

Fig. 11. Deposit of the slip.

\section{CONCLUSIONS}

We successfully prepared membrane support from natural material with a low cost compared in the other commercial supports. The membrane support was prepared by extruding ceramic paste derived from natural Sahara Moroccan clay and sintered at $950{ }^{\circ} \mathrm{C}$. The properties of the support are satisfying in terms of porosity and mechanical and structural

The performed filtration tests confirmed that the support prepared, based on Saharan clay, is suitable in the development of a microfiltration membrane. This membrane could find an economical application in the wastewater treatment.

\section{REFERENCES}

[1] Lee, S.H., Chung, K.C., Shin, M.C., Dong, J.I., Lee, H.S., Auh, K.H., Preparation of ceramic membrane and application to the cross flow microfiltration of soluble waste oil, Materials Letters, vol. 52, 2002, p. 266-271. 
[2] Gaucher, C., Jaouen, P., Comiti, J., Legentilhomme, P., Determination of cake thickness and porosity during cross-flow ultrafiltration on a plane ceramic membrane surface using an electrochemical method, Journal of Membrane Science, vol. 210, 2002, p. 245-258.

[3] Tataru, L., Nedeff, V., Barsan, N., Panainte-Lehadus, M., Mosnegutu, E., Chitimus, D., Studies on the application of hollow Fiber membranes in the field of ultrafiltration, Journal of Engineering Studies and Research, vol. 22, 2016, p.42-53.

[4] Van Gestel, T., Vandecasteele, C., Buekenhoudt, A., Dotremont, C., Luyten, J., Leysen, R., Van der Bruggen, B., Maes, G., Alumina and titania multilayer membranes for nanofiltration: preparation, characterization and chemical stability, Journal of Membrane Science, vol. 207, 2002, p. 73-89.

[5] Romanos, G.E., Steriotis, T., Kikkinides, A., Kanellopoulos, E.S., Kasseelouri, N.K., Ramsay, J.D.F., Langlois, P., Kallus, S., Innovative methods for preparation and testing of $\mathrm{Al}_{2} \mathrm{O}_{3}$ supported silicalite-1 membranes, Journal of the European Ceramic Society, vol. 21, 2001, p. 119-126.

[6] Khemakhem, S., Larbot, A., Ben Amar, R., New ceramic microfiltration membranes from Tunisian natural materials: application for the cuttlefish effluents treatment, Ceramics Internationals, vol. 35, 2009, p. 55-61.

[7] Hajjaji, M., Kacim, S., Alami, A., Bouadili, A., El Mountassir, M., Chemical and mineralogical characterization of a clay taken from the Moroccan Meseta and study of the interaction between its fine fraction and methylene blue, Applied Clay Science, vol. 20, 2001, p. 1-12.

[8] Saadi, L., Jabry, E., Moussa, R., Caractérisation physico-chimique d'argile marocaines, Journal de Chimie Physique, vol. 88, 1991, p. 2347-2353.

[9] Lahsini, A., Bentama, J., Addaou, A., Rafiq, M., Caracterisation physico-chimique et étude du frittage d'une argile destinée à l'élaboration de membrane de filtration tangentielle, Journal de Chimie Physique, vol. 95, 1998, p. 1001-1019.

[10] Kakali, G., Perraki, T., Tsivilis, S., Badogiannis, E., Thermal treatment of Kaolin: The effect of mineralogy on the pozzolanic activity, Applied Clay Science, vol. 20, 2001, p.73-80.

[11] Bouzid Rekik, S., Bouaziz, J., Deratani, A., Baklouti, S., Study of ceramic membrane from naturally occurring-kaolin clays for microfiltration applications, Periodica Polytechnica Chemical Engineering, vol. 61, no. 3, 2017, p. 206-215.

[12] Saffaj, N., Persin, M., Younsi, S.A., Albizane, A., Cretin, M., Larbot, A., Elaboration and characterization of microfiltration and ultrafiltration membranes deposited on raw support prepared from natural Moroccan clay: application to filtration of solution containing dyes and salts, Applied Clay Science, vol. 31, 2006, p. 110-119.

[13] Khemakhem, S., Larbot, A., Ben Amar, R., New ceramic microfiltration membranes from Tunisian natural materials: Application for the cuttlefish effluents treatment, Ceramics International, vol. 35, 2009, p.55-61.

[14] Saffaj, N., Préparation de membrane d'ultrafiltration à base d'oxyde de titane et d'aluminate de zinc sur supports d'argiles Application à la filtration de sels métalliques et des colorants, Thèse, Université Hassan IIMohammedia, Maroc, 2004.

[15] Du, Y., Zuo, H., Mechanical properties and microstructures of regenerated cement from waste concrete, Journal of Engineering Studies and Research, vol. 23, 2017, p.7-13. 